\title{
Feijoo en la obra de José de Viera y Clavijo
}

\author{
Victoria Galván GonZÁleZ \\ Universidad de Las Palmas de Gran Canaria
}

CES.XVIII, núm. 17 (2007), págs. 149-172. 
RESUMEN: En este artículo se ofrece al lector una aproximación a la influencia de la obra de Feijoo en la de José de Viera y Clavijo. Se rastrean algunas coincidencias entre las obras de ambos por citas explícitas o por asunción por parte de Viera de los postulados del benedictino. Como en todo trabajo de esta naturaleza, no se pretenden excluir otras referencias o lecturas en el ilustrado tinerfeño. Pero su propia declaración de lo determinante que fue en sus primeros años la lectura de las obras de Feijoo basta para considerar la trascendencia de este autor. Además, se aprecia que esta presencia es más notable en la primera etapa de la biografía de Viera en los años previos a su traslado a Madrid en los años setenta del siglo XVIII.

Palabras clave: Pensamiento e influencia de Feijoo. Ilustración canaria. Historia. Ciencia. Educación. Elocuencia. 
La huella literaria del benedictino Benito Jerónimo Feijoo y Montenegro en la obra de José de Viera y Clavijo es reconocida por el propio autor en sus memorias literarias:

Más véase aquí que, en medio de la lóbrega noche de estos miserables estudios, llegó de improviso a alumbrarle una ráfaga de feliz claridad. Por fortuna le dio a leer un amigo suyo las obras críticas de Feijoo; y al paso que las iba leyendo, o más bien devorando, se iba presentando a su razón otro nuevo mundo científico, y a su espíritu otros inmensos horizontes. Así fueron estas como las primeras semillas de cultura y de literatura sensata $[\ldots]^{1}$.

En ellas nos dice que el descubrimiento de la obra crítica de Feijoo en sus primeros años de lectura y de estudio le abrió nuevos horizontes y perspectivas de conocimiento. De tal suerte que pudo vivir, según sus palabras, en el siglo de las luces en que muchos no viven. A partir de aquí, de la cita explícita que lleva a cabo en su obra histórica, en sus cartas o en la poesía, de la asunción de algunos dictados feijonianos, la crítica ha juzgado determinante su influencia en el repertorio de lecturas y de conocimientos de Viera. Por ejemplo, A. Millares Torres, en su Biografías de canarios célebres ${ }^{2}$, reproduce similares palabras a las escritas por Viera en sus memorias. Ya en el siglo Xx, J. Rodríguez Moure, en su Juicio crítico del historiador de Canarias don José de Viera y Clavijo, arcediano de Fuerteventura, del mismo modo que el historiador canario, declara al respecto:

Fue la causa de este cambio de pensar en nuestro historiador la lectura del Teatro Crítico de Feijoo, obra que le proporcionó un amigo y que lo decidió a estudiar los

1 José de Viera y Clavijo, Memorias que con relación a su vida literaria escribió don José de Viera y Clavijo, Arcediano de Fuerteventura, Dignidad de la Santa Iglesia Catedral de Gran Canaria, de la Academia de la Historia e historiógrafo de las Islas Canarias, cuando se le pidieron de Madrid para una nueva edición del artículo de su nombre en la «Biblioteca Española de los mejores escritores del reinado de Carlos III», escrita por don Juan Samper y Guarinos, en J. DE Viera y Clavijo, Diccionario de Historia Natural de las Islas Canarias, ed. dirigida y prologada por M. Alvar, Madrid, Excma. Mancomunidad de Cabildos de Las Palmas, Plan Cultural, 1982, págs. LIX-LX.

2 Agustín Millares Torres, Biografías de canarios célebres, Las Palmas de Gran Canaria, Eds. Edirca, 1982, vol. II. 
idiomas francés, inglés e italiano, con algunas nociones del griego, por el deseo que tenía de poder conocer en sus fuentes los autores que Feijoo cita en su Teatro ${ }^{3}$.

Agustín Espinosa en 1935, en su conocido ensayo «Sobre el signo de Viera», nos dice que «Viera está junto a Feijoo, anunciador de su caudal signo» ${ }^{4}$. Alejandro Cioranescu, por otra parte, es el primer estudioso en detenerse a analizar con más detalle lo que hay de Feijoo en la obra y en la personalidad de Viera. En su artículo «Viera y Clavijo y la cultura francesa» ${ }^{5}$, reconoce que Viera participa del espíritu crítico y del buen juicio del autor gallego. El espíritu inquieto del polígrafo canario casa bien con el cartesianismo, el criticismo, el racionalismo francés, el empirismo y el sensualismo, que son centrales en Feijoo. Juzga Cioranescu que la preocupación por el conocimiento, buscada en las fuentes francesas, la incorpora desde su lectura del Teatro Crítico Universal, dando a entender que la presencia de otras referencias es más ensanche que descubrimiento de las novedades científicas que conocerá a lo largo de su existencia.

Todos aquellos que se han acercado ulteriormente a la obra de Viera suscriben estas valoraciones del estudioso rumano, que sitúan a Feijoo como una referencia nuclear en su evolución intelectual, paralela a la que representan Voltaire o Rousseau, entre otros. Me propongo en estas páginas revisar algunos aspectos procedentes de la obra de Feijoo en Viera, por citas directas de su obra o por afinidad intelectual y de talante. Para ello me centraré tanto en ideas, conceptos y apreciaciones comunes a ambos autores, como en las citas directas de la obra de Feijoo en la de Viera.

\section{El rol de historiador}

En relación con el oficio de historiador, las coincidencias en programa de intenciones son evidentes. Si cotejamos el discurso 8 del libro IV del Teatro Crítico Universal con las palabras de Viera en la obra histórica y en algunas de las cartas que se conservan ${ }^{6}$, se constata su toma de conciencia de la dificultad de

3 José Rodríguez Moure, Juicio crítico del historiador de Canarias don José de Viera y Clavijo, arcediano de Fuerteventura, Santa Cruz de Tenerife, Imprenta de A. J. Benítez San Francisco, 1913, pág. 9; reeditado en la colección Biblioteca de Rodríguez Moure, La Laguna (Tenerife), Artemisa Ediciones, 2006, pág. 29.

4 Agustín Espinosa, Sobre el signo de Viera, La Laguna (Tenerife), Instituto de Estudios Canarios, 1935, pág. 19.

5 Alejandro Cioranescu, «Viera y Clavijo y la cultura francesa», en Estudios de Literatura española y comparada, Universidad de La Laguna, 1954, págs. 207-248.

6 Vid. en especial las siguientes cartas: «Al mismo Sr. Dn. Juan Antonio de Urtusáustegui», Aranjuez, 18/5/1774; «Al mismo Sr. Dn. Juan Antonio de Urtusáustegui», Madrid, 15/4/1777; «Dn. Fernando de Molina 
escribir historia, la apelación a la verdad, aunque sea incómoda, la necesidad de distanciarse de las fábulas, de las supersticiones que la tradición ha transmitido, el cuidado del estilo, el rechazo de la prolijidad, de la afectación y la búsqueda de la imparcialidad. Pero por encima de estos principios está el recurso a la crítica, la sujeción a los dictados del análisis racional en el estudio de los hechos pasados. El escepticismo racional de Feijoo se sustenta en la fiabilidad de los textos en los que se apoya el conocimiento del pasado, como pone de manifiesto en «Reflexiones sobre la historia», el trabajo más completo del benedictino sobre esta temática, a juicio de F. J. Fernández Conde ${ }^{7}$, en «Divorcio de la historia y la fábula» o los dos ensayos «Glorias de la nación española», como casos concretos. Feijoo desmonta los testimonios apoyados en leyendas y en mitos, porque a su juicio pueden ser objeto de falseamiento. Concluye que las fábulas y la historia corren parejas. Desmitifica, por tanto, la fe religiosa en un pasado estable y fijo, en un pasado idealizado por las fuentes antiguas o en la idea de una edad gloriosa de la investigación en el pasado, que el presente debe mantener. Sus palabras y sus reflexiones suponen un varapalo para la manera tradicional de concebir la historia en la España contemporánea a ambos autores.

Aunque conviene matizar que se ha discutido mucho acerca de la credibilidad científica de los discursos feijonianos en relación con el trabajo más filológico y crítico, por ejemplo, de G. Mayans y Siscar, Flórez, Martí o los novatores valencianos. Lo cierto es que la obra de Feijoo actuó como revulsivo en la cultura española contemporánea, también en la lectura de las tradiciones y de la mística del pasado glorioso español. Un estudioso como A. Mestre ${ }^{8}$ cuestiona la imparcialidad de Feijoo en el momento de aplicar sus propuestas metodológicas al pasado de España y, en particular, en la interpretación de los asuntos que afectan a la tradición católica. A juicio de Mestre, Feijoo es más proclive a Bossuet que a Voltaire en estos asuntos. Cabe tener en cuenta que el benedictino

\footnotetext{
y Quesada. Regidor de Tenerife», Madrid, 12/1/1773; «Al mismo Dn. Fernando de Molina», San Ildefonso, 3/8/1773; «Al mismo Dn. Fernando de Molina», Madrid, 3/2/1774; «Al mismo Dn. Fernando de Molina», Madrid, 12/8/1774; «Marqués de la Villa de San Andrés y Vizconde de Buen Paso», Madrid, 9/4/1776. Vid. Copiador de algunas Cartas Familiares escritas por Dn. J. V. C. (I, II, III, IV), ms. autógrafo, Biblioteca de la Real Sociedad Económica de Amigos del País de La Laguna; Cartas de don José de Viera y Clavijo a diversas personalidades, introducción, selección y notas de A. Luque Hernández, Santa Cruz de Tenerife, Goya Ediciones, 1984 y Algunas cartas familiares de José de Viera y Clavijo (1770-1807), ed., introd. y notas y apéndice de R. Fernández Hernández, Santa Cruz de Tenerife, Ediciones Idea, 2006.

F. J. Fernández Conde, «Feijoo y la ciencia histórica», en Studium Ovetense. Revista del Instituto Superior de Estudios Teológicos del Seminario Metropolitano de Oviedo, 4 (1976), pág. 76.

8 Antonio Mestre SAnchís, «Reflexiones sobre el marco político y cultural de la obra del P. Feijoo», en Apología y crítica de España en el siglo XVIII, Madrid, Marcial Pons Historia, 2003, págs. 167-183. Vid. también A. Mestre Sanchís, Despotismo e Ilustración en España, Barcelona, 1976; Influjo europeo y herencia hispánica. Mayans y la Ilustración valenciana, Valencia, 1987.
} 
no es historiador, sino divulgador y ensayista; facetas que los ilustrados valencianos, como el deán Martí y el propio Mayans, le reprochaban como argumento de inconsistencia científica.

También sobre la posición de Feijoo ante la historia, A. Mestre ${ }^{9}$ expone que los admiradores en principio de su obra modifican su juicio al comprobar, como dice Piquer, atacado por Feijoo en sus Cartas eruditas, que la lectura desordenada de las obras del benedictino ha producido más sabios aparentes que cualquier otra. Mayans va más allá en el trabajo historiográfico en relación con el método y promueve un trabajo crítico profundo y riguroso. Por su parte, Feijoo es un divulgador, así lo juzgaban los novatores valencianos, y no se entretenía en pequeños detalles o en consultar archivos. Por ejemplo, Segura acusó a Feijoo de no haber trabajado con prurito de historiador en el caso de Savonarola. Por tanto, para Mestre ${ }^{10}$ Feijoo, desde la óptica metodológica, no consulta libros originales, ni fuentes de primera mano, sino que elabora sus juicios a partir de lo recogido en obras de consulta y de diccionarios. Su trabajo, como se dijo líneas arriba, se ciñe a las funciones de divulgador y de ensayista.

Por su parte, Viera pretende ser científico, riguroso y analítico en la revisión del pasado de las Islas Canarias. Acomete, como es sabido, la primera historia moderna de las islas. Por ello es reputado como «el Salustio canario», aunque Serra Ráfols ${ }^{11}$ afirme que no fue en realidad un historiador, sino un literato que cultivó la historia. Por el contrario, M. Menéndez Pelayo ${ }^{12}$, en el estudio que dedica a la obra dramática de Lope de Vega Los guanches de Tenerife y la conquista de Canaria, juzgó a Viera como el historiador más clásico y excelente de los historiadores de Canarias.

La pregunta que puede formularse es si Viera fue tan feijoniano como pretende en su perspectiva histórica al trasladarla a su objeto de trabajo, toda vez que ello implica determinar cuestiones espinosas y controvertidas en la toma de posición frente a las tradiciones religiosas o a los orígenes. En lo que se refiere al programa de intenciones, Viera suscribe las tesis feijonianas, no compartidas en exclusiva por el benedictino, ni estimadas por originales, como es sabido. A Viera le interesan, asimismo, las referencias literarias y las lecturas que se desprenden de la obra del benedictino. No hay constancia textual, al respecto,

\footnotetext{
9 Antonio Mestre Sanchís, Historia, fueros y actitudes políticas: Mayans y la historiografía del siglo XVIII, Valencia, Publicaciones del Ayuntamiento de Oliva, Serie Tesis Doctorales, 1970, pág. 82.

10 Ibid., págs. 79-86.

11 Elías Serra RÁfols, «Viera y Clavijo, historiador», en J. DE Viera y Clavijo, Historia de Canarias, Santa Cruz de Tenerife, Goya Ediciones, 1950, pág. LIX.

12 Marcelino Menéndez Pelayo, Estudios sobre el teatro de Lope de Vega, t. V (Crónicas y Leyendas dramáticas de España), ed. de E. Sánchez Reyes, Madrid, Consejo Superior de Investigaciones Científicas, MCMXLIX, pág. 297.
} 
de que conociera la obra de Mayans; por lo menos en su etapa anterior al viaje a Madrid en 1770, cuando ya habían acabado en el territorio nacional las polémicas entre distintas concepciones de la historia con los protagonistas antes mencionados.

Para calibrar la modernidad de Viera ${ }^{13}$ en su rol de historiador importa tanto su praxis como sus posturas teóricas. En lo teórico, aparte de los prólogos que preceden a los tomos de su obra histórica, se conserva un discurso dirigido a la Real Academia de la Historia, «Oración gratulatoria leída en la Real Academia de la Historia de Madrid el día 25 de Febrero de 1774» ${ }^{14}$. Aquí Viera se sitúa en el horizonte de expectativas académicas sobre la historia y sus objetivos: la defensa de la verdad de los sucesos; resucitar lo que se ha oscurecido de la Antigüedad; desterrar las fábulas y las mentiras y, sobremanera, la necesidad de que los autores nacionales aborden la historia del país ante el empuje de los extranjeros en apropiarse de los asuntos nacionales. Viera resume las preocupaciones sobre la disciplina de la historia auspiciadas por la Academia de la Historia, que él parece compartir de modo ferviente. Con el antecedente de la publicación de De re diplomatica de Mabillon en 1681, la historiografía ilustrada ${ }^{15}$ se caracteriza por la centralidad otorgada al documento, por promover la crítica del mismo y por la metodología conducente a establecer la verdad. La Real Academia de la Historia se propuso formar un catálogo de fuentes documentales, que un Corner desacredita por practicar aquello que quiere desterrar. Estos presupuestos, compartidos por buena parte de los ilustrados, están en Feijoo años antes, pero también en los novatores valencianos.

Con respecto a Viera, en los prólogos escritos por el autor para sus Noticias de la Historia General de las Islas Canarias, los objetivos que se propone guardan íntima relación con los presupuestos de Feijoo en su intención de corregir los errores que sobre las islas habían vertido los historiadores precedentes, como Núñez de la Peña. Su plan estará presidido por la imparcialidad, la verdad, la modestia, la razón y el buen gusto. Respecto al método, apela a la exigencia

\footnotetext{
13 Vid. Alejandro Cioranescu, «Viera y Clavijo y la filosofía de la historia», en Syntaxis, 4 (1984), págs. 57-74.

14 José de Viera y Clavijo, «Oración gratulatoria leída en la Real Academia de la Historia de Madrid el día 25 de Febrero de 1774», ms. copia de Maffiotte sobre un ms. original de J. de Quesada y Déniz, en A. Millares Carlo y M. Hernández Suárez, Biobibliografía de Escritores Canarios (siglos XVI, XVII y XVIII), en colaboración con A. Vizcaya Carpenter y A. Millares Sall, t. VI (Q-Z), ed. al cuidado de J. A. Martínez de la Fe, Madrid, Ediciones del Cabildo de Gran Canaria, 1993, págs. 457-458.

15 Vid. Guy Bourdé-Hervé Martin, Las escuelas históricas, Madrid, Akal Universitaria, 1992, págs. 89-102; José Lozano, «La crítica del documento», en El discurso histórico, Alianza Universidad, Madrid, 1994, págs. 68-79; José Antonio MaravalL, «Mentalidad burguesa e idea de la Historia en el siglo XVIII», en Estudios

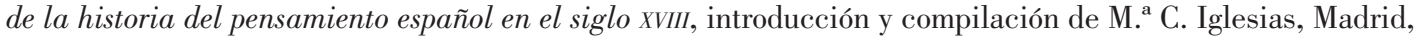
Biblioteca Mondadori, 1991, págs. 113-138.
} 
de ordenar a partir del caos de los datos e informaciones recopilados. Sobre la narrativa de los sucesos recurre a la moderación sin desatender la imparcialidad histórica. Recalca que no ha temido ser desagradable por ser útil. Como es recurrente, cita la conocida declaración aristotélica acerca de los fines de la historia, que ha de contar las cosas como realmente sucedieron y no como debieron ser, con todo lo que ello implica. Las coincidencias se concretan en la compartida concepción de la historia como algo más que la acumulación de datos, pues el historiador debe elegir entre las noticias más relevantes y ordenarlas de manera adecuada. Por tanto, presentar los hechos de forma conexa de acuerdo a un plan razonado con pleno sentido. Idea que, por otra parte, está en Voltaire, otra de las referencias presentes en la obra de nuestro autor ${ }^{16}$. En ello insiste Viera en su correspondencia y en su obra histórica, como rezan estas palabras del prólogo al tomo I de sus Noticias: "Que no se ha aparecido hasta ahora la pluma hábil e imparcial que, formando con algún tino el enlace de las memorias, esparcidas acá y allá, nos ofrezca un todo dispuesto con una más que mediana regularidad y perfección» ${ }^{17}$. $\mathrm{O}$ en una carta remitida al marqués de la Villa de San Andrés en 1776:

[...] y no se conocerá el inmenso trabajo que ha sido menester para ordenar, coser, aclarar y no omitir lo útil, omitiendo lo inútil. Vs. que sabe los papelorios que han venido de allá, conocerá quánto quebradero de cabeza habrá sido menester para sacarles la sustancia, y hacerla potable y dulce ${ }^{18}$.

Todo ello implica una serie de riesgos y peligros, que preocupan por igual a ambos autores. Feijoo en su discurso «Reflexiones sobre la historia» alerta acerca de las mentiras y de las falsedades en las que pueden incurrir los historiadores con abundantes ejemplos al respecto:

16 Habría que considerar si Viera toma esta idea directamente de Voltaire o a través del propio Feijoo, conocedor de las tesis del autor galo, que elogia su Histoire de Charles XII roi de Suède. A. Cioranescu, en el artículo citado en la nota 13 , habla de Voltaire como una de las fuentes del pensamiento histórico de Viera. Con respecto a Feijoo, parece que sus posiciones historiográficas están más cerca de Bossuet. Al respecto, declara F. J. Fernández Conde en el trabajo citado en la nota 7: «La cosmovisión feijoniana adolece del mismo defecto que la del obispo de Meaux y se hace acreedora del reproche formulado por Votaire a su compatriota en Essai sur les moeurs et l'esprit des nations (1756), cuando afirma que "(Bossuet) parace haber escrito únicamente para insinuar que todo el mundo ha sido hecho para el pueblo judío"» (art. cit., pág. 95). El mismo investigador subraya que para Feijoo Cristo es el centro de la historia y su siglo el verdadero siglo de oro. Con respecto a Viera, se ha insistido en su apuesta por la secularización en su teoría de la historia.

17 José de Viera y Clavijo, Noticias de la Historia General de las Islas Canarias, introducción y notas de A. Cioranescu, índice onomástico y de materias de M. G. Martínez, Santa Cruz de Tenerife, Goya Ediciones, 1982, t. I, pág. 12.

18 José de Viera y Clavijo, Algunas cartas familiares de José de Viera y Clavijo (1770-1807), ed. cit., pág. 129. 
Pero la mayor arduidad está en acertar con lo que más importa; esto es, con la verdad. Dijo bien un gran Crítico moderno, que la verdad histórica es muchas veces tan impenetrable, como la filosófica. Esta está escondida en el pozo de Demócrito; y aquella, ya enterrada en el sepulcro del olvido, ya ofuscada con las nieblas de la duda, ya retirada a espaldas de la fábula. Creo se puede aplicar a la Historia lo que Virgilio dijo de la Fama, porque son muy compañeras, y aquella muy frecuentemente hija de esta ${ }^{19}$.

Viera, por su parte, insiste en que la verdad será su principal objeto de trabajo y a lo largo de las páginas de sus Noticias de la historia general de las Islas Canarias desmiente las numerosas fábulas y quimeras que sobre varios asuntos han circulado en la tradición histórica de las islas, como la anécdota de unos africanos sin lengua que se establecieron en Fuerteventura y Lanzarote o los errores de Núñez de la Peña sobre la conquista de Lanzarote y Fuerteventura. Sobre esto último, el autor señala que quien consulte la obra de Núñez de la Peña y la suya «creerá sin duda que escribimos la historia de dos países muy diversos ${ }^{20}$, aunque no está aludiendo a la diferencia interpretativa entre los dos autores, sino a las diferencias metodológicas habidas entre ambos. O, por decirlo de otro modo, Viera marca una distancia infranqueable entre los predecesores, que afrontan la tarea historiográfica desde una óptica acientífica, y los contemporáneos como él, insertos en la órbita científica. Aquí Viera se coloca del lado de la modernidad historiográfica que se promueve en la centuria con evidentes intenciones reformistas, como declara J. A. Maravall:

Parece, pues, plenamente comprobable que la exigencia de verdad en Historia, la búsqueda afanosa de documentos y datos, la labor crítica de rehacer aquella sobre esas bases reputadas auténticas, la condenación de criterios fundados en valores tradicionales que ofuscan el conocimiento de los hechos y, finalmente, la exaltación del papel educativo de la Historia, reconstruida con nuevos métodos, es una actitud que se liga a la posición de los grupos reformadores y que, consiguientemente, se relaciona con los intereses que mueven a $\operatorname{estos}^{21}$.

Viera, además, refleja el mito recurrente de la superioridad de los modernos frente a los antiguos, cuando menos en lo tocante a su fe en la idea de progreso

19 Benito Jerónimo Fejjoo y Montenegro, «Reflexiones sobre la historia», en Teatro Crítico Universal, t. IV, discurso VIII, Madrid, Imprenta Blas Román, a costa de la Real Compañía de Impresores y Libreros, 1775, págs. 172-173.

20 José de Viera y Clavijo, op. cit., t. I, libro III, pág. 291.

21 Maravall, op. cit., pág. 122. 
y de avance aneja al presente de la monarquía carlostercista, apoyo borbónico que suscribe Feijoo. La lectura del pasado está tamizada por el rescate de un pasado glorioso de acuerdo a las expectativas modernas. Así Viera ensalza la figura de un Tostado, la monarquía de los primeros Austrias, en consonancia con la tendencia imperante en el entorno ilustrado. Sobre su lectura del pasado nacional cabe traer a colación las palabras de F. Sánchez Blanco a propósito del Elogio de Felipe V:

José de Viera y Clavijo, que gana el concurso, presenta a Felipe V como heredero y síntesis de ambas dinastías, en mera continuidad y sin ruptura aparente con el pasado. No habla de la perversión del carácter nacional bajo los Austrias. Establece la conexión con las glorias de Carlos I [...] Paralelamente, la historiografía literaria confirma la misma línea volviendo a cantar las glorias del Siglo de Oro y a denostar las novedades del presente siglo, precisamente el siglo de los Borbones. Ese cambio de perspectiva histórica cuadra bien con la orientación hacia el pasado y la tradición de la Contrarreforma católica ${ }^{22}$.

\section{Las tradiciones religiosas y devociones populares}

Parece estar fuera de duda que las coincidencias detectadas en las obras respectivas de Viera y de Feijoo deben mucho al programa historiográfico ilustrado y preilustrado ${ }^{23}$. Pero conviene acercarnos a aquellos casos concretos en los que este prontuario de intenciones se enfrenta con obstáculos. Al respecto, está sujeta a dificultades la interpretación de las tradiciones relativas a la religión cristiana y a las devociones populares. En la práctica, Feijoo oscila y se muestra moderado. Y declara lo siguiente:

Mas cuando no hay argumento positivo contra las tradiciones, sí sólo el negativo de la falta de monumentos que las califiquen, como sucede por la mayor parte a las de nuestra Nación, dos reglas me parece se deben seguir: una en la Teórica, otra en la Práctica; una dictada por la Crítica, otra por la prudencia. La primera es suspender el asenso interno, ó prestar un asenso débil, acompañado del recelo de que la ilusión

22 Francisco Sánchez-Blanco, El absolutismo y las luces en el reinado de Carlos III, Madrid, Marcial Pons, Historia, 2002, págs. 251-252.

23 Vid. Jesús Pérez Magallón, «La reconstrucción de la historia y el espíritu crítico», en Construyendo la modernidad: la cultura española en el tiempo de los novatores (1675-1725), Madrid, Consejo Superior de Investigaciones Científicas, 2002, págs. 63-183. 
ó embuste de algún particular haya dado principio a la opinión común. Puede ser esta verdadera y puede ser falsa, porque la creencia popular es como la fama: Tam ficti, pravique tenax, quam nuntia verit. 75. La segunda es, no turbar al Pueblo en su posesión: ya porque tiene derecho a ella siempre que no puede apuntarse la verdad, ya porque de mover la cuestión no puede cogerse otro fruto que disensiones en la República literaria, y dicterios contra el que emprendió la guerra. Cuando yo, por más tortura que dé al discurso no pueda pasar de una prudente duda, me la guardaré depositada en la mente, y dejaré al Pueblo en todas aquellas opiniones que, ó entretienen su vanidad, ó fomentan su devoción. Sólo en caso que su vana creencia le pueda ser por algún camino perjudicial, procuraré apearle de ella mostrándole el motivo de la duda, y entonces le clamaré con el Profeta: Popule meus, qui te beatum dicunt, ipsi te decipiunt, \& viam gressuum tuorum dissipant. (Isai. cap. 3.) ${ }^{24}$.

Viera al hablar de una de las tradiciones populares religiosas de mayor arraigo en las Islas Canarias, la aparición de la Virgen de la Candelaria ${ }^{25}$, afirma con prudencia que no es objeto de su interés criticar el juicio que sobre su autenticidad emitieron fray Alonso de Espinosa, Antonio de Viana, fray Juan de Abreu Galindo y Núñez de la Peña. Recoge los testimonios de acuerdo a la ley de la historia al referir sólo las circunstancias extraordinarias del suceso con los datos de los anticuarios. Pero no se detiene a enjuiciar las circunstancias de la historia. Es decir, su celo histórico se detiene en el momento de llevar hasta el límite de la crítica y de la razón las causas de este hecho milagroso. Viera al respecto también, como Feijoo, prefiere mantener al pueblo en sus creencias, cuando no tiene argumentos sólidos para contrarrestar lo que percibe próximo a las fábulas.

En este aspecto, ambos discreparían de Mayans y Siscar, por ejemplo, quien animado por un deseo de reforma religiosa no cede en su esfuerzo por no aceptar todo aquello que no esté bien documentado. Su rigor crítico en materias históricas sagradas o profanas excede el de Feijoo. Bien es cierto que este último no pretende hacer historiografía como Mayans ${ }^{26}$, que entiende que la reforma de la religión pasa por fijar y publicar todos los documentos y la cronología relativos a las tradiciones populares, la historia sagrada y las devociones loca-

24 Benito Jerónimo Feijoo y Montenegro, «Glorias de España. Primera Parte», en op.cit., págs. 385-386.

25 José de Viera y Clavijo, Noticias de la Historia General de las Islas Canarias, ed. cit., t. I, libro III, págs. 276-280.

26 Vid. Antonio Mestre Sanchís, Ilustración y reforma de la Iglesia. Pensamiento político-religioso de don Gregorio Mayans y Siscar (1669-1781), Valencia, Publicaciones del Ayuntamiento de la Oliva, 1968, págs. 113, 165-181. 
les. Hay que deslindar, por tanto, la cuestión de fe del estudio crítico de las tradiciones religiosas no fundamentadas. Aquí coincidirían estos tres autores, en nada sospechosos de incredulidad religiosa. Pero en el objetivo común de reforma cultural de la nación, que tiene en la historia uno de sus pilares, Feijoo y Viera estarían más próximos, frente a un Mayans ${ }^{27}$, más preocupado por crear un método científico que altere las estructuras culturales españolas con especial énfasis en el rigor, la técnica y un conocimiento depurado de las fuentes, como explica Mestre ${ }^{28}$.

Con respecto a Viera es interesante atender a sus palabras en el análisis de la imagen de san Juan Evangelista y su sudor, tras afirmar que sólo un crítico caviloso negaría el hecho a tenor de los documentos conservados:

Pero, como en este género de prodigios se vale Dios de ciertas causas naturales que sabe dirigir a los fines que se propone su providencia, me parece que nada rebajaría de este portento aquel que intentase examinarlo a humana luz, sometiendo su parecer, en todo, a los que fueren o más timoratos o más entendidos. Nada ha perdido de su veneración el sudor prodigioso de Nuestro Señor en Getsemaní, porque el sabio y pío Calmet hubiese publicado la disertación sobre sus calidades y posibilidad natural y física ${ }^{29}$.

A continuación, Viera informa de las razones técnicas por las que la imagen que se venera en la Iglesia de la Concepción de La Laguna desprende ese sudor milagroso. En este caso, como en los restantes, Viera actúa de acuerdo al método de probar los sucesos extraordinarios con la intervención de la razón y de los testigos, tal y como procede Feijoo en aras de discriminar los verdaderos milagros de las supercherías ${ }^{30}$, aunque se incurra en contradicciones.

27 Debe subrayarse la importancia de su Carta-dedicatoria a José Patiño, de 1734, como documento inestimable de un proyecto de reforma cultural con el propósito de sacar a España de su postración y decadencia cultural. En el plano estrictamente eclesiástico su Espejo Moral se concreta en la reforma de la Iglesia. Vid. J. Pérez Magallón, En torno a las ideas literarias de Mayans, Alicante, Instituto de Cultura Juan-Gil Albert, Diputación de Alicante, 1991.

28 Antonio Mestre Sanchís, Historia, fueros y actitudes políticas: Mayans y la historiografía del siglo XVIII, ed. cit., pág. 80.

29 José de Viera y Clavijo, op. cit., t. II, pág. 673.

30 Al respecto son ilustrativos del modo de operar de Feijoo en lo tocante a creencias religiosas los discursos «Milagros supuestos», $6 .^{\circ}$ del tomo III del Teatro Crítico Universal; «Tradiciones populares», «Regla matemática de la fe humana», discursos 16 y $1 .^{\circ}$ del tomo V; «Purgatorio de San Patricio», «Cuevas de Salamanca y Toledo, y Mágica de España», discursos $6 .^{\circ}$ y $7 .^{\circ}$ del tomo VII, entre otros. De las Cartas eruditas y curiosas, «Sobre la multitud de milagros», carta 43, tomo I; «Examen de milagros», carta 11, tomo II, entre otras cartas. En todos los casos Feijoo procede del mismo modo: como todas las tradiciones, incluso las descabelladas, tienen autoridades en las que fundarse, él considera aquellas que se atengan a falsedad y que contravengan los dictados del escepticismo o de la Iglesia. 
Sobre la cuestión religiosa, Feijoo no se enfrenta al dogma. No lleva la razón ni el desengaño a los límites de la teología y de la dogmática. En este sentido, coincide Viera con sus objetivos desmitificadores, dado que nunca se separó de sus creencias ni de la autoridad eclesiástica. Todo ello a pesar del acercamiento e interés por teorías científicas que ponen en tela de juicio la cosmovisión cristiana ortodoxa. Es esta, no obstante, una actitud recurrente en la Ilustración española. Ello no obsta para el deseo de reformar la Iglesia y la lucha contra la superstición religiosa en Feijoo y en Viera y Clavijo.

La crítica de la religión está estrechamente unida en la centuria que nos ocupa al asunto de la historia sagrada. Viera aborda la historia eclesiástica del archipiélago y Feijoo lleva a sus discursos y cartas todas aquellas creencias, tradiciones y milagros que conforman la historia de las tradiciones en España para someterlos al escepticismo científico. Sólo se pueden afrontar los errores en materia religiosa, si se tiene un conocimiento cabal de la historia de la religión en España. A partir de aquí, Feijoo cuestiona algunos mitos y figuras (purgatorio de san Patricio, los hechos mágicos en la Cueva de Toledo y Salamanca, etcétera), aunque, como se ha dicho, defienda tradiciones no bien documentadas en aras de un propósito social. Viera y Clavijo con perspectiva histórica lleva a cabo un recorrido por las tradiciones devocionales populares y por la historia de la Iglesia en Canarias. El cuarto tomo de su obra histórica ${ }^{31}$ aborda la religión de los antiguos canarios, la creación del obispado de Rubicón, la lista de los obispos y la erección del tribunal de la Inquisición. El libro XVII del cuarto libro desarrolla la historia eclesiástica de Canarias y el libro XVIII aborda las fundaciones religiosas.

Para salir de cualquier duda acerca de la postura religiosa de Viera y Clavijo son ilustrativas las palabras iniciales al libro XVI del tomo cuarto, cuando declara que la religión de los guanches era la más apropiada para un pueblo de bárbaros que no conoce aún la revelación. La razón, que lo une a Feijoo, es que Viera comenta que no se daban los primitivos isleños a las idolatrías, a las supercherías o a los derramamientos de sangre en los sacrificios practicados por otras naciones y reprobados por buena parte de los ilustrados. Su análisis histórico de la Iglesia canaria pone de manifiesto su empeño en erradicar todas las fábulas y mentiras que habían circulado acerca de los orígenes del cristianismo en Canarias con el capítulo que denomina «Predicación fabulosa de algunos santos en nuestras

$31 \quad$ No pueden obviarse, por otra parte, sus trabajos eclesiásticos desarrollados en sus funciones de arcediano de Fuerteventura en la Catedral de Canaria: redacción de las constituciones y estatutos de la Iglesia de Canaria; las actas capitulares desde 1514 hasta 1799; resumen de los antiguos estatutos de la Iglesia de Canaria; sermones; panegíricos; la composición de un libro pedagógico como El Hyeroteo o Derechos del Presbiterado. 
islas» ${ }^{32}$. De modo similar a Juan de Ferreras — referencia fundamental en la renovación de la historiografía española, defendido por Feijoo, a quien Viera cita en numerosas ocasiones en la obra, en su Historia de España-, Mayans o Martínez, Viera no da por buenas aquellas narraciones históricas religiosas que no están apoyadas en testimonios fidedignos. Viera no da crédito cuando la fuente no es fiable, porque no queden pruebas, por la inverosimilitud, por la incredibilidad de un testigo o por la imposibilidad de un hecho. Son importantes, además, los argumentos apoyados en la geografía o en la cronología. En este ejemplo citado, Viera y Clavijo desmiente la veracidad de la venida y de la predicación de san Avito a las Islas en tiempos de Trajano, porque en ese periodo cronológico no hay noticias precisas de evangelización.

\section{Historias fabulosas}

Otro ejemplo ilustrativo en materia histórica se aprecia en el análisis que acomete Viera de la creencia en lo que titula «la famosa cuestión de San Borondón» ${ }^{33}$, en donde cita al propio Feijoo en su discurso X, «Fábula de las Batuecas, y Países imaginarios», del tomo IV del Teatro Crítico Universal, para hacer acopio de todos los argumentos y de los datos esgrimidos por los historiadores, por los cronistas y por los testimonios de la aparición de la mentada isla. Con ello pretende mostrar al lector la disparidad de juicios, razonamientos o creencias para que, finalmente, este asuma la libertad de decidir entre las varias opciones: es una de las islas de las Afortunadas, como dicen Mabillon, las vidas de san Maclovio y san Blandano, que circula en cierta tradición, que Núñez de la Peña y Abreu Galindo citan recogida en un manuscrito perdido en la Catedral de Canaria; los testimonios de los habitantes de La Palma, Hierro, Gomera y suroeste de Tenerife, que afirman haberla contemplado, aunque Viera les replique con el argumento de la acumulación de nubes; testimonios fidedignos de los que afirman haber desembarcado en San Borondón; referencias de Ptolomeo, Aristóteles o la mitología, etcétera.

Para Viera el lector tiene la última palabra, si es necesario tomar partido en asuntos de esta naturaleza. Su postura imparcial se aprecia en la manifestación de las diferentes posibilidades, cuando repasa todas las explicaciones posibles. Afirma que por qué no podría darse la circunstancia de que la isla sea un día un lugar conocido y frecuentado. Luego declara que puede explicarse por las

32 Viera y Clavijo, op. cit., t. IV, libro XVI, págs. 450-452.

33 Viera y Clavijo, ibid., t. I, libro I, págs. 83-112. 
refracciones de las cumbres de algunas tierras distantes, que se presta a interpretaciones múltiples. Más próxima a su manera de ver el fenómeno es la idea de la imposibilidad de probar su existencia por su búsqueda infructuosa a lo largo del tiempo. Aunque traslade al lector la responsabilidad de optar, manifiesta sus propios juicios al respecto (por ejemplo, afirma: «Estas apariciones, que ya hacemos vanidad de despreciar, eran la gran quimera de nuestros abuelos [...]» ${ }^{34}$ ).

En este capítulo concreto de su obra histórica, Feijoo es citado en tres ocasiones. Viera cita las referencias a la isla de San Borondón del discurso X del tomo IV del Teatro Crítico Universal y el discurso X del tomo I, «Cometas». En este último discurso, Viera resalta la reflexión de Feijoo sobre las calamitosas circunstancias que acompañan a la aparición de los cometas, aunque la frase exacta no está en el texto de Feijoo, pues todo parece indicar que Viera efectúa una paráfrasis («contentos — como se explica aquí el Ilmo. Feijoo- con un recurso infeliz de fenómenos desgraciados» ${ }^{35}$ ).

Las otras dos citas están tomadas de modo exacto del discurso $\mathrm{X}$ del tomo IV. En ellas Feijoo explica la aparición de san Borondón por reflexión en alguna nube de la calidad de un espejo. La segunda cita del benedictino cierra el capítulo en el que Viera refuta la idea de la permanente presencia de nubes que ocultan la vista de la isla o la corriente extraordinaria del agua que impide el acceso de las embarcaciones. De los argumentos de interés que Viera reproduce para los lectores, los de Feijoo son determinantes en este asunto. Hay que señalar la coincidencia en el procedimiento argumentativo, pues ambos pretenden desmontar las hipótesis barajadas desde la aplicación de los criterios de la razón y de la verosimilitud. Por ejemplo, al cuestionar cómo es que una isla que se ha divisado, visitado y pretendido haber arribado a ella — se pregunta Viera-, no puede verse desde el pico Teide en los días claros, si la razón negativa esgrimida es la del cubrimiento de las nubes.

La diferencia esencial entre ambos reside en que, en este caso concreto, Feijoo niega toda posibilidad de veracidad, pues su discurso se asienta en el descrédito y en la desarticulación de los países imaginarios. Pero Viera, a pesar de inclinarse, dado el cúmulo de argumentos, por la postura feijoniana, cierra el episodio apelando a la libertad de elección del lector. Se diría que intenta dar carta de naturaleza a la pluralidad de interpretaciones ${ }^{36}$, cuando no se tiene la certeza absoluta, signo de modernidad literaria.

34 Viera y Clavijo, ibid., pág. 88.

35 Ibid., pág. 95.

36 Sobre otras investigaciones relacionadas con la isla, Vid. E. BENITo RuAno, «San Borondón», octava isla canaria, Casa-Museo de Colón, Seminario de Historia de América de la Universidad de Valladolid, 1979; Dolores CoRbella y J. Medina, Noticias de la Isla de San Borondón, La Laguna (Tenerife), Instituto de Estudios Canarios, 1997. 


\section{Historia natural}

Feijoo es nuevamente mentado en la obra histórica de Viera en lo relativo a la historia natural y acerca de la maravilla natural del Árbol del Hierro. En materia de historia natural, Feijoo declara:

Que las fábulas, que se introducen en la Historia Civil, una vez admitidas, se eternicen en la creencia de los hombres, no hay que extrañar; porque los sucesos, y siglos pasados no hay modo de hacerlos otra vez presentes, para explorar cuánto se alteró la verdad de ellos, o por la poca sinceridad, o por la mucha credulidad de los Historiadores. Pero que con las fábulas, que se introdujeron en la Historia Natural, suceda lo mismo, es digno de la mayor admiración: porque siendo la naturaleza siempre la misma, siempre tenemos a los ojos el desengaño. Esta es prueba concluyente de que el vulgo es de cera para admitir las impresiones de las fábulas, y de bronce para retenerlas. En ninguna materia hay tanta pobreza de Escritores juiciosos, y fieles como en la Historia Natural. El Canciller Bacon, que sin duda leyó mucho, dice que no halló escrito algo sobre las maravillas de la naturaleza digno de fe: Narrationem gravem, \& severam de heteroclitis, \& mirabilibus naturae diligenter examinatam, \& fideliter descriptam non invenio \{(a) De Augment. Scient. lib. 2$\}^{37}$.

Viera dirá en el prólogo a su Diccionario de Historia Natural ${ }^{38}$ que la historia natural del propio país es uno de los estudios más importantes, pero que no es suficiente que sea un estudio vulgar e imperfecto, sino que debe ser científico para que se pueda discernir a fondo la clase, la especie a la que pertenece una planta o un animal. Coinciden ambos, por tanto, en la urgencia de conocer a fondo los fundamentos de la historia natural.

Volviendo al capítulo del citado Árbol del Hierro ${ }^{39}$, Viera reproduce en su Noticias de la Historia General de las Islas Canarias los argumentos de Feijoo, que declara que, aunque geógrafos e historiadores afirman que existe, Thomas Cornelio, en su Diccionario Geográfico, y el padre Tallandier, misionero jesuita

37 Benito Jerónimo Feijoo y Montenegro, «Historia Natural», en Teatro Crítico Universal, ed. cit., discurso II, t. II, págs. 27-28.

38 José de Viera y Clavijo, Diccionario de Historia Natural de las Islas Canarias, estudio introductorio de V. Galván González, prólogo de J. de Viera y Clavijo, actualización de terminología científica de W. Wilpret de la Torre, A. Brito Hernández y J. A. Lorenzo Gutiérrez, La Laguna (Tenerife), Nivaria Ediciones, 2005, págs. 49-50.

39 Vid. A. S. Hernández GutiérRez, Garoé. Iconografía del Árbol del Agua, Canarias [sic], Dirección General del Patrimonio Histórico-Viceconsejería de Cultura y Deportes, 1998; Berta Pico y Dolores CoRBELLA, «La tradición documental sobre el garoe y los relatos de viajeros franceses», en Homenaje al Profesor D. Jesús Cantera Ortiz de Urbina, Madrid, Servicio de Publicaciones de la Universidad Complutense, 1997, págs. 201-215. 
francés, citado en las Memorias de Trévoux, en 1715, desmienten su existencia y no dudan en reputarlo fingido. Viera, asimismo, añade más opiniones contrarias al Árbol del Hierro: Bacon de Verulamio, La Maire, Nablot, Barbot, Sarmiento y Martineau-Duplessis afirman que se trata de una ficción. Expone a continuación los relatos de Gonzalo de Oviedo, Livio Sanuto, Juan Botero, Linschoten, Luis Jackson, Viana, Du Bartas, Pedro Mexía. Para confirmar su tesis de que no es un árbol fabuloso, pero sí un árbol santo, trae a colación el relato de fray Juan Abreu y Galindo. Tras citar un fragmento, Viera dice que cualquier crítico se habría creído la existencia de este árbol. La nómina de autores que refrendan su tesis de la verdadera existencia continúa con Nieremberg, los escritores franceses de la historia de Juan de Béthencourt, Cairasco, Bartolomé García del Castillo, Davity, Dapper, Maller, La Croix, José del Olmo, etcétera.

Concluye el capítulo refutando las fuentes de Feijoo, Taillandier y Thomas Corneille, que, a su juicio, no contaron con la información suficiente. Finaliza con la alusión a la controversia originada por Feijoo, que dio pie a que el Conde de la Gomera exigiera un reconocimiento jurídico en la isla del Hierro. Varios testigos de la isla afirman la tradición, el sitio donde estuvo y mostraron las reliquias del árbol de las albercas. Con estos argumentos Viera contradice a Feijoo, pero ataca a los dos autores citados, Taillandier y Corneille, sin decir que el benedictino también erró en este asunto. Las palabras finales de Viera son elocuentes al respecto:

Concluyamos, pues, sin temor de ser desmentidos, que la bebida de los antiguos herreños corría en cierto modo por cuenta de una providencia poco común, y que los isleños, circunvecinos debían mirarlos como unos hombres favorecidos de la naturaleza $a^{40}$.

Por otra parte, en la voz correspondiente al «Árbol de la isla del Hierro (Arbor mirabilis Garoe)» en su Diccionario de Historia Natural ${ }^{41}$, no menciona a Feijoo, sino a Bernáldez y a Abreu y Galindo, defensores del árbol. Dice que los datos que se manejan se apoyan en tradiciones relatadas en las crónicas y que aún se ignoran todos los detalles de la historia del árbol que fue destruido por un huracán en 1610. Lo que llama la atención es que Viera trae a colación numerosas fuentes, muchas de ellas no estrictamente científicas, Cairasco o Abreu y Galindo, entre otras, y que la base de su argumento está finalmente ligada a la tradición, que él cree válida, o en la frecuente mención del árbol en varias

40 Viera y Clavijo, Noticias de la Historia General de las Islas Canarias, t. I, ed. cit., pág. 145.

41 Viera y Clavijo, op. cit., págs. 112-113. 
fuentes. No obstante, este modo de proceder no es del todo acientífico, pues buena parte de las leyendas pasan a formar parte de la historia como fuentes. Es evidente que aquí no se acude a documentos basados en experimentaciones contrastadas, sino en relatos de testigos que afirman haber visto el árbol o de restos físicos como las reliquias. Viera actúa de acuerdo a la práctica común a partir de Bayle y otros de someter a la crítica los documentos y los testimonios conservados sobre un hecho concreto, dando crédito Viera, en este caso, por la recurrencia de testimonios que se difunden por la vía de relatos.

En relación con la historia natural aquí mencionada, es relevante el concepto de Naturaleza que tanto Viera como Feijoo defienden. Ambos parten de la convicción establecida en el siglo XVIII del carácter estable, fijo y maravilloso de esta entidad. En ambos se aprecia su idealización de la llamada diosa Naturaleza, que Feijoo con palabras de Aristóteles llama demonian. Podemos citar frases de Viera, en especial, en el prólogo a su diccionario, en las que se expresa subyugado por la magnificencia de la Naturaleza. De todos modos, esta visión es general en todos los autores de la centuria. Pero sí llama la atención que en sus primeros años en La Laguna Viera defienda el estudio de la naturaleza, la necesidad de conocer sus misterios, como comparte Feijoo, con otros tantos coetáneos.

Otra idea compartida es la dependencia de las maravillas de la naturaleza de la creación divina. Igual que Feijoo refuta el ateísmo, Viera hace depender los prodigios de la máquina natural del poder de la creación de Dios. En ambos se constata que la superioridad natural se debe a la mano rectora del creador y que la ciencia no hace más que desvelar sus potencialidades, frente a los errores que el vulgo ignorante comete. Esto está en Linneo o en Newton, por otra parte, pues pocos fueron los que asumieron la independencia de la materia de cualquier idea teísta. Véanse al respecto estas declaraciones de Feijoo y Viera:

En este mismo sentido, y por la misma razón se puede decir, que es demonian la Naturaleza. Son sus operaciones, y efectos tan admirables, que es preciso reconocer en la actividad de sus causas un genio elevado, sublime, misterioso, que por más que vuele en su alcance el discurso, se queda siempre muy lejos de nuestra comprensión [...].

No hay obra alguna en toda la Naturaleza, que no sea rasgo de una mano Omnipotente, y de una Sabiduría infinita. Admira el Vulgo el artificio de una Muestra de Londres: incomparablemente es más delicada, y sutil la fábrica de una hormiga. Lo que digo de la Hormiga, extiendo a otro cualquier compuesto natural. Ninguno hay, cuya composición no sea estupenda, no sea prodigiosa. Aristóteles conoció muy bien esta verdad. No hay cosa, dice, en todo el Universo, en quien no ocurra 
algo que admirar: Cum nulla res sit Naturae, in qua non mirandum aliquid inditum videatur. (Lib. I. de Part. Animal. cap. 5) ${ }^{42}$.

[...] Después que sucesivamente se ocuparon en el miserable estudio de las caducas opiniones y delirios de los hombres, se acabaron de desengañar en el nuestro, de que el de la Historia Natural, y de todas sus subalternas, la Agricultura, la Medicina, la Astronomía, la Física, la Química, la Economía, es el legítimo estudio de la realidad, porque es el estudio de las obras del Creador y por consiguiente de su sabiduría y su omnipotencia, de su magnificencia, de su providencia, de su bondad. ¡Oh Dios! ¡qué prodigios! ¡qué estudio!33.

\section{Ciudadanía y nación}

Otro aspecto vinculado al rol del historiador es el compromiso con un proyecto de sociedad, de nación y de ciudadano, con el servicio público que se desprende de todo ello. En virtud de una perspectiva histórica y de la necesidad de que cada nación cuente con una historia propia, rigurosa y critica, Viera imagina su utilidad para la sociedad del presente. Se aprecia una dimensión social y política de su empresa. En este sentido, se sabe que en el siglo XVIII se piensa en un proyecto de reforma global, en el que la formación del ciudadano es parte indisociable de la idea de estado, de comunidad o de sociedad. El conocimiento de la historia es el pilar en el que se asienta una sociedad que quiere asumirse a sí misma como moderna, como explica en el prólogo a su obra histórica:

los isleños han tenido necesidad de una historia natural y civil, para que sean más conocidas en el mundo sus glorias, sus hazañas, su nobleza, sus servicios, sus talentos, sus méritos... Y que cuando aplico mis arbitrios y débiles fuerzas, por un patriotismo casi sin ejemplar, a la introducción de este útil trabajo, sólo pretendo promover los verdaderos intereses de las Canarias, sirviéndolas con el tributo que les deben mis cortas luces ${ }^{44}$.

A continuación, recorre la escasa suerte de las islas a la hora de recopilar los hechos históricos, que los predecesores, tanto los bárbaros como los europeos, no llevaron a cabo e insiste en que en un siglo más ilustrado, consciente de la utilidad de la historia, es obligado derramar luces en medio de las tinieblas.

42 Benito Jerónimo Fejoo y Montenegro, «Maravillas de la Naturaleza», en Teatro Crítico Universal, discurso VI, t. VI, Madrid, Andrés Ortega, a costa de la Real Compañía de Impresores y Libreros, 1774, pág. 226.

43 José de Viera y Clavijo, Diccionario de Historia Natural de las Islas Canarias, ed. cit., págs. 56-57.

44 José de Viera y Clavijo, op. cit., págs. 13-14. 
El proyecto que emprende, por su parte, Feijoo tiene, sin duda, un destinatario colectivo. Desde sus prólogos a los discursos al Teatro Crítico Universal y a las Cartas eruditas, el autor gallego inicia su andadura crítica con el objeto de desterrar las falsedades y los errores, término este nuclear en su obra, que el vulgo en sus diferentes ámbitos sostiene. Sus palabras tienen un claro marchamo público, pues no es otro el fin de sus discursos y cartas que, como declara en el prólogo al primer tomo de su conocida obra: «que mi designio en esta Obra es desengañarle de muchas, que por estar admitidas como verdaderas, le son perjudiciales; y no sería razón, cuando puede ser universal el provecho, que no alcanzase a todos el desengaño» ${ }^{45}$. En otros lugares de su obra nos dirá: «Yo escribo principalmente para España. ¿Y qué es más útil para España?» ${ }^{46}$.

Por otra parte, en un texto de 1768 de Viera y Clavijo como el Elogio del Barón de Pun, escrito en el seno de la tertulia de Nava — que de modo no gratuito menciona a Feijoo desde el comienzo, cuando declara que el Barón de Pun nació cuatro años después que el benedictino — se comenta la necesidad de las luces, del progreso y del compromiso de todos aquellos que poseen intelecto, como el propio Barón de Pun, alter ego de la tertulia y de Viera. Se afirma, además, la defensa de la urgencia de que todos contribuyan a adelantar la república de las letras ${ }^{47}$. En este texto, de 1768, se cita a Feijoo en estos términos:

Es necesario confesar, que en todos los estados de la monarquía española han sido regularmente los escritos de Dn. Fr. Benito Feijoo los grandes misioneros que obraron cualesquiera conversiones considerables en los entendimientos que padecían algún extravío ${ }^{48}$.

Este texto, que puede reputarse como epítome de los proyectos renovadores que suscriben Viera y la tertulia, ofrece en sus páginas un prontuario de intenciones desmitificadoras, desterradoras de errores y de necedades, que coincide de pleno con los discursos en boga, pero que textualmente coloca en primer término a Feijoo por ser el benedictino, no el único en su tiempo, el bastión de la causa del progreso. Parece harto probable que en esta etapa tinerfeña de Viera y Clavijo,

45 Fejoo y Montenegro, «Prólogo», en op. cit., págs. LXXX-LXXXI.

46 Feijoo y Montenegro, «Sobre el adelantamiento de las Ciencias, y Artes en España», carta XXXI, en Cartas eruditas y curiosas (1742-1760), t. III (1750), Madrid, Imprenta Real de la Gazeta, a costa de la Real Compañía de Impresores y Libreros, t. II (nueva impresión), pág. 361.

47 Sobre el compromiso de los escritores con la República de las letras, vid. el sugerente estudio de J. Álvarez Barrientos, Los hombres de letras en la España del siglo XVIII. Apóstoles y arribistas, Madrid, Editorial Castalia, 2006.

48 José de Viera y Clavijo, Elogio del Barón de Pun, ms. 10 (1), copia de Alejo de Ara, Biblioteca Municipal de Santa Cruz de Tenerife. 
Feijoo se erige en modelo y referencia para acometer proyectos similares en el ámbito insular. El siguiente fragmento del texto mencionado es harto elocuente:

Diego Dávila no sabía entonces que su nombre estaba destinado para causar en los entendimientos una revolución y trastornar el modo de pensar de la más sana parte de sus paisanos.

Así mientras una especie de Teología escolástica, cargada de sutilezas ingeniosas (a la verdad útiles hasta cierto punto, pero casi siempre excesivas) se olvidaba de la Sagrada Escritura de los Concilios de los SS. Padres, de la historia de la Iglesia; y demás fuentes originales para irse tras una metafísica vana, cabilosa y aérea: mientras una moral cómoda, y un probabilismo capcioso y relajado arrastraba con su cola la tercera parte de los casuistas, y la generación de los Pedros, y Marcias, Licios y Bertas: mientras una filosofía de palabras, toda erizada de sofismas, de tramoyas, y de quintas esencias llenaba las cabezas de viento y el corazón de vanidad: mientras una oratoria loca y descomedida profanaba todo lo más santo con paradoxas frívolas, textos desfigurados, gracietas indecorosas, y falsas ponderaciones, sostenidas de no sé qué ayre de estilo bárbaro, impuso, cláusulas, pedante, y afectado de oropeles, sin nada de elocuencia varonil y buen gusto: mientras las preocupaciones antiguas, los errores comunes, la sabiduría aparente, la superstición, el fanatismo y el entusiasmo del amor propio era el patrimonio de una nación noble, devota, ociosa, e ignorante: El Barón de Pun, aunque arrebatado a impulsos del común turbillon, no dexaba de sentir en su alma las primeras semillas de la verdad, que de antemano lo iban preparando al desengaño; y las luces que debían ponerlo algún día al nivel del siglo XVIII ${ }^{49}$.

Estas propuestas se hallan recogidas en los discursos y cartas de Feijoo. Valgan como ejemplo, las coincidencias en el sintagma «sabiduría aparente», «el entusiasmo del amor propio» o «los errores comunes», empleados con frecuencia en la obra del benedictino. Los errores son el objeto de su pluma desde el primer discurso del tomo I del $T C U$, «Voz del pueblo» y desde su prólogo. La sabiduría aparente es el título del discurso 8 del tomo II del TCU. La esterilidad del amor propio, del amor por lo particular, ajeno a lo exterior en perjuicio de un verdadero amor de la patria, es objeto del discurso $\mathrm{X}$ del tomo III del $T C U$, «Amor de la patria, y pasión nacional». Por no mencionar los conocidos ataques contra la filosofía escolástica y la oratoria barroca, en los que coinciden Feijoo y Viera, como tantos otros contemporáneos. Por otra parte, el vocablo «desengaño» es clave en el lenguaje feijoniano, pues expresa a la perfección el medio del que se vale para su programa de utilidad reforma nacional.

\footnotetext{
49 Ibid.
} 


\section{La educación}

En relación con la necesidad de traer las luces a la nación, el tema de la educación se torna esencial en el proyecto ilustrado. En la etapa lagunera de Viera la redacción de los Memoriales del Síndico Personero en 1764 expresan con nitidez su pensamiento pedagógico con claras coincidencias con el de Feijoo. No es, no obstante, la única fuente a la que recurre ${ }^{50}$. En esta obra la urgencia de promover los intereses de la República mueven a Viera a solicitar al Cabildo de Tenerife unas reformas básicas para su consecución. De acuerdo a las directrices vigentes en los pensadores contemporáneos, la educación es el centro de atención. Como dice en el Memorial Segundo:

[...] si se deja que a los errores de la ignorancia, en que naturalmente nacen nuestros jóvenes, añada sus falsas preocupaciones la mala educación, ¿qué nombre respetable adquirirán ellos, ni la Patria en el mundo? El estudio, Señor, es quien corrige los unos y disipa las otras. Nacidos para vivir en sociedad y ser miembros de un cuerpo cuyas ventajas son amables; destinados por la providencia para ocupar con dignidad los empleos de la República y de la Iglesia es sola la instrucción quien puede sostener nuestro mérito mucho tiempo. Ella sola nos da el buen gusto, la policía, la dulzura y los bellos modales; ella sola la exactitud y la limpieza a nuestros discursos ${ }^{51}$.

Pone el énfasis en el Memorial Segundo en la formación de los maestros al exponer una carencia generalizada en la pedagogía del siglo XVIII. La formación de estos es el paso imprescindible para ello. Imagina Viera al preceptor entregado a la lectura, entre otros, de Pluche, de Fleury, del Teatro Crítico Universal. Con ello rubrica nuestro autor la preeminencia que concede al benedictino para introducir cambios sensibles en el universo educativo y público. Con estas lecturas el maestro conducirá a sus pupilos a evitar los errores que desde temprana edad se instalan en el hombre.

Coincidencias con Feijoo se aprecian, por otra parte, en la convicción de la necesidad de una perfecta formación de los futuros maestros, pues de su ignoran-

50 Acerca de esta obra de Viera pueden consultarse los trabajos de Olegario NEGrín FAJARDo, «El Síndico Personero General o el estado de la enseñanza tinerfeña en la segunda mitad del siglo XVIII y sus posibles reformas», en Educación e Ilustración en España, Barcelona, Universidad de Barcelona, 1984, págs. 276-285; Estudios de historia de la educación en Canarias, Las Palmas de Gran Canaria, Ediciones del Cabildo Insular de Gran Canaria, 1998.

51 José de Viera y Clavijo, Memoriales del Síndico Personero, ed., introducción y notas de Olegario Negrín Fajardo, Madrid, Ediciones del Cabildo Insular de Gran Canaria, págs. 82-83. 
cia proceden todos los males. Estos deben enseñar con celo, con afán por estimular a sus alumnos, sin transmitir los conocimientos con enfado, severidad y con rechazo a los castigos. Acerca de ello se pronuncia Feijoo en sus cartas, como en su Carta XXXI: «Sobre el adelantamiento de las Ciencias, y Artes en España»:

Yo veo bien, que para introducir esa mudanza de método hay algunas dificultades, cuales son, en primer lugar la falta de noticias en los Lectores, y Catedráticos de Artes, y en segundo, la falta de Libros para adquirirlas. Pero la mayor de todas está de parte de los Profesores antiguos, o viejos, a lo menos de muchos de ellos, los cuales, mirando como desprecio de su existimada Ciencia, que en las Escuelas se empiece a enseñar lo que ellos ignoran, es natural se valgan de la autoridad que les dan sus años, y sus honores para hacer odiosa esta novedad literaria ${ }^{52}$.

Feijoo, como Viera, promociona el estudio de las ciencias modernas, de la Física, las Matemáticas, la Astronómica, la Botánica, la Geográfica o la Historia Natural, para evitar la pobreza de España en estas materias o de la isla de Tenerife, respectivamente.

\section{La elocuencia}

Un aspecto que reviste interés en el probable influjo del pensamiento de Feijoo en Viera ${ }^{53}$ es el concepto de elocuencia que ambos sostienen. Bien conocida es la aseveración del benedictino sobre la naturalidad en la definición de la elocuencia. La carta VI del tomo II de sus Cartas eruditas y curiosas pudo ser lectura de Viera para la redacción de su Memorial quinto de El Síndico Personero General, que se abre con una cita de Quintiliano, autor presente también en la carta de Feijoo, y con referencias a Fleury. Bien es cierto que en el origen de las tesis de Viera sobre esta materia opera el antiescolasticismo dominante y su propósito de reformar la oratoria sagrada. En el proyecto de reforma ciudadana que nos propone Viera en la obra mencionada juzga imprescindible la creación de una cátedra pública de elocuencia, que define de este modo:

La elocuencia, aquel instrumento feliz con que los mortales se comunican las mejores pasiones y que quizá es el único testigo auténtico de la superioridad de un

52 B. J. Feijoo y Montenegro, «Sobre el adelantamiento de las Ciencias y Artes en España», carta XXXI, en Cartas eruditas y curiosas, Imprenta Real de la Gaceta, Madrid, 1774, pág. 388.

53 Vid. Victoria Galván González, La obra literaria de José de Viera y Clavijo, Las Palmas de Gran Canaria, Ediciones del Cabildo Insular de Gran Canaria, 1999. 
hombre sobre otro; aquel arte divino hecho para hablar al sentido y para imponer silencio a la razón es sólo el que, puesto entre las manos de un hombre extraordinario, puede triunfar de toda una nación descaminada, y es el que entre nosotros ni se ama ni se cultiva ${ }^{54}$.

A continuación, explica con detalle cómo la enseñanza de la elocuencia en Tenerife ha fallado por pretender reducir el genio a preceptos y por querer suplir el talento natural que requiere el dominio de esta materia por la vía errónea de las reglas de la retórica. Y afirma que sólo la naturaleza «puede criar hombres elocuentes ${ }^{55}$.

Tanto Feijoo como Viera creen en la necesidad de la gracia y en la imposibilidad de aprender el genio si no se posee en origen. A partir de aquí el estudio de las buenas obras, la lectura de libros adecuados y la perfección del estilo completará el proceso. Aunque sostienen objetivos diferentes en sus respectivos textos, ambos están persuadidos de la necesidad del estudio y de la lectura. Pero si no hay predisposición, es una tarea vana. Las palabras de Feijoo son muy precisas al respecto: «Mas nunca pasaré, que pueda producir primores. La gala de las expresiones, la agudeza de los conceptos, la hermosura de las figuras, la majestad de las sentencias, se las ha de hallar cada uno en el fondo del propio talento» ${ }^{56}$. Viera insiste más en su texto en la necesidad del estudio, a partir del talento natural, y Feijoo en la imposibilidad de ser elocuente, si no hay calidad natural.

A modo de conclusión, para matizar la influencia de Feijoo sobre Viera, conviene subrayar que las propuestas del benedictino, como se sabe, adelantan, junto con los novatores, Cabriada, Cardoso o Tosca, los presupuestos ilustrados ulteriores y que las lecturas de Viera en esta primera etapa de su biografía no se limitan al autor gallego. Pero sí se aprecia, como dijera Cioranescu o A. Espinosa, que su lectura fue decisiva. Con toda probabilidad las ideas recogidas por Feijoo causaron un gran efecto en nuestro autor, pues en las obras escritas en el período de La Laguna se dejan sentir sus ecos con más fuerza que en el resto de sus producciones.

\footnotetext{
54 Viera y Clavijo, op. cit., pág. 121.

55 Ibid., pág. 122.

56 Benito Jerónimo Feijoo y Montenegro, Cartas eruditas y curiosas, t. II, Madrid, Imprenta Real de la Gazeta, a costa de la Real Compañía de Impresores y Libreros, 1773, pág. 50.
} 